\title{
A Year to Evaluate the Neonatal and Obstetric Outcome in Covid 19 Positive Pregnant Women in Abu Dhabi UAE
}

\author{
Riem Farah* (), Rimpi Datta, Raoya Farah, Fahmida Nasir Patel \\ Mediclinic Al Noor Hospital, Abu Dhabi, The United Arab Emirates \\ Email: *rsyfarah@yahoo.co.uk
}

How to cite this paper: Farah, R., Datta, R., Farah, R. and Patel, F.N. (2022) A Year to Evaluate the Neonatal and Obstetric Outcome in Covid 19 Positive Pregnant Women in Abu Dhabi UAE. Open Journal of Pediatrics, 12, 26-32.

https://doi.org/10.4236/ojped.2022.121004

Received: November 15, 2021

Accepted: February 7, 2022

Published: February 10, 2022

Copyright $\odot 2022$ by author(s) and Scientific Research Publishing Inc. This work is licensed under the Creative Commons Attribution International License (CC BY 4.0).

http://creativecommons.org/licenses/by/4.0/ (c) (i) Open Access

\begin{abstract}
Covid 19 epidemic has caused a lot of concern especially in the obstetric and neonatal populations. The fact that it is a new disease and the fact that there are sparse studies available have doubled our worries. Our study provides some answers. This a retrospective study carried out in Mediclinic Al-Noor hospital in Abu Dhabi. Our study revealed no adverse effects on the neonates and no vertical transmission. Given the physiologic and immune function changes in pregnancy, they might be considered at a higher risk of developing more complications, but it needs a longer duration of the study with larger sample size. Statistical analysis could not be possible in our study due to the smaller sample size, and we plan to continue the study further in the future to obtain a larger pool of data to validate the findings more accurately. The incidence of covid positive mothers might not reflect today's covid situation because we carried out the study during the lockdown and there might be an increase in the incidence after lockdown.
\end{abstract}

\section{Keywords}

COVID 19, Neonates

\section{Background}

COVID 19 pandemic is the most recent health issue facing the world. Its effect on pregnancy and the unborn foetus is still under a lot of evaluation [1]. This single center study is done to evaluate the effect on the mother and the foetus of pregnant women who were positive for COVID 19 anytime during their gestation.

\section{Aim/Objective}

The purpose of the study is to highlight the possible impact on the mother and 
the foetus due to COVID 19 with the purpose of improvement in feto-maternal outcome by interventions and precautions which can be implemented

\section{Method}

This is a retrospective type of study over the period of 1 year.

Data of all pregnant women with POSITIVE COVID 19 results who were attending the Mediclinic Al Noor Hospital, Abu Dhabi, over the study period was collected from the hospital electronic medical record system and MALAFFI (medical information exchange platform of Abu Dhabi, UAE).

Inclusion criteria: Pregnant women with positive COVID 19 result during the course of gestation attending our institution over the study period.

Exclusion: Pregnant women with negative COVID 19.

As it is a retrospective study where all the COVID 19 positive patients were included without exception, the bias was eliminated.

The babies of mothers who were positive at the time of delivery were evaluated and tested for COVID 19 within 48 hours of birth.

\section{Results and Discussion}

A total of 1145 pregnant women were booked in the maternity department over a duration of 1 year out of which 20 cases were confirmed to be positive for COVID 19.

Based on the severity of symptoms, we found that 9 (45\%) mothers were asymptomatic, and 11 (55\%) had mild symptoms such as cough, fever, fatigue, myalgia and anosmia. We did not need to admit any of the COVID Positive pregnant women to the intensive care unit during our study duration.

There were 9 patients who were in home quarantine and 11 were confined to hospital (Figure 1).

Out of the total 20 COVID positive pregnant women, 25\% (5 patients) were detected in $1^{\text {st }}$ trimester, $20 \%$ (4 patients) in $2^{\text {nd }}$ trimester, $55 \%$ (11 patients) in $3^{\text {rd }}$ trimester (Figure 2).

Out of the 11 patients who needed hospital admissions, 7 were due to obstetric conditions, 2 had comorbidities: age $>35$ years and high BMI with asthma and 2 were symptomatic with high grade fever.

Two preterm deliveries occurred ( $10 \%$ of total Covid positive pregnant population) which could be due to obstetric reasons (twins, PPROM with incompetent cervix) and cannot be directly co-related to COVID 19 infection.

\section{Neonatal Outcome}

Total of 17 babies ( 1 pair of twins) with a history of COVID positive in mothers have delivered till now in our hospital over the study period.

Babies with birth weight $<2.8 \mathrm{~kg}$ were 7 (41\%) out of which 3 were preterm babies and appropriate for gestational age. Two of them were with early onset small for date babies and 2 were with foetal growth restriction. 


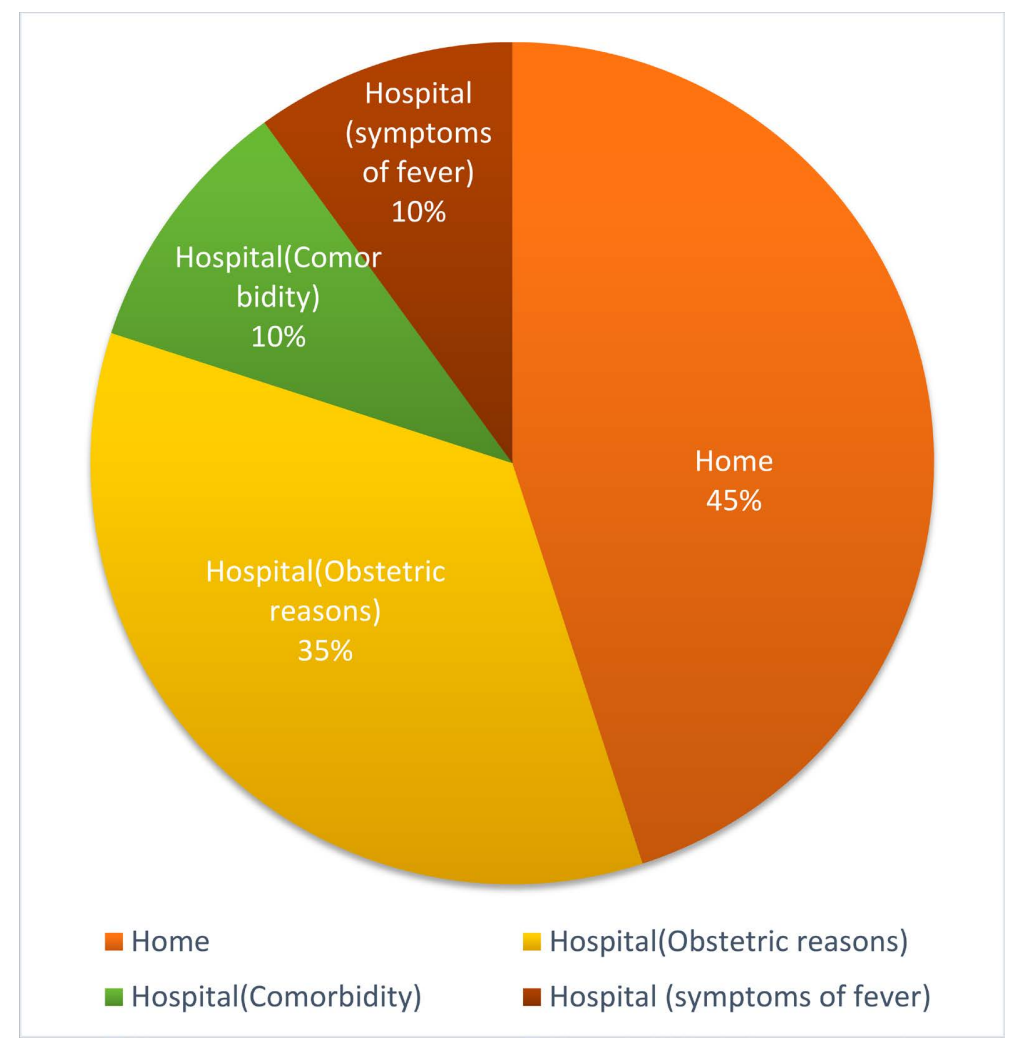

Figure 1. Percentage of place of delivery.

\section{COVID Positive pregnancy}

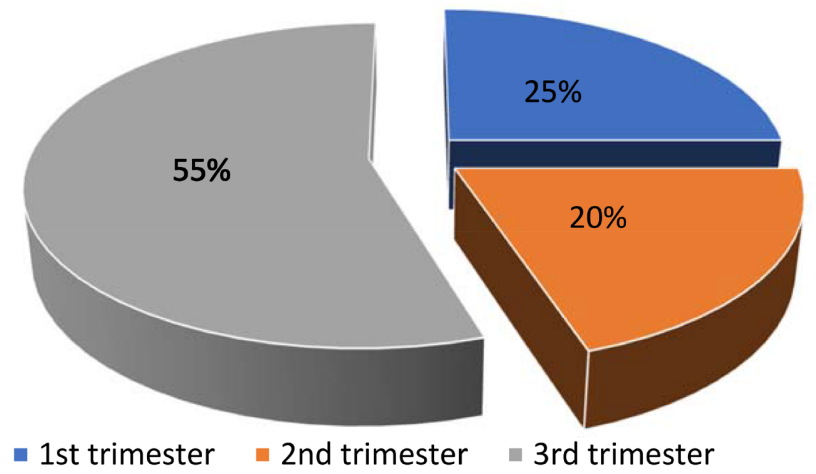

Figure 2. Percentage of Covid positive mothers according to trimesters.

The mothers of growth restricted babies were detected with COVID 19 in their third trimester and were of Arab and South Asian ethnicity. Most of the babies did well in their postnatal period and the NICU admissions were for prematurity and neonatal jaundice (Figure 3 \& Figure 4).

$20(1.7 \%)$ of total pregnant women (1145) attending or admitted to our hospital over a duration of 1 year were confirmed positive for COVID 19.

The total positive cases with pregnancy were 20 . Five patients (25\%) were detected in $1^{\text {st }}$ trimester, 4 patients (20\%) in the $2^{\text {nd }}$ trimester, 11 patients $(55 \%)$ in the $3^{\text {rd }}$ trimester. None of the pregnant women needed Intensive care.

Two preterm deliveries occurred which represents $10 \%$ of the total Covid 


\section{Maternal Outcome}

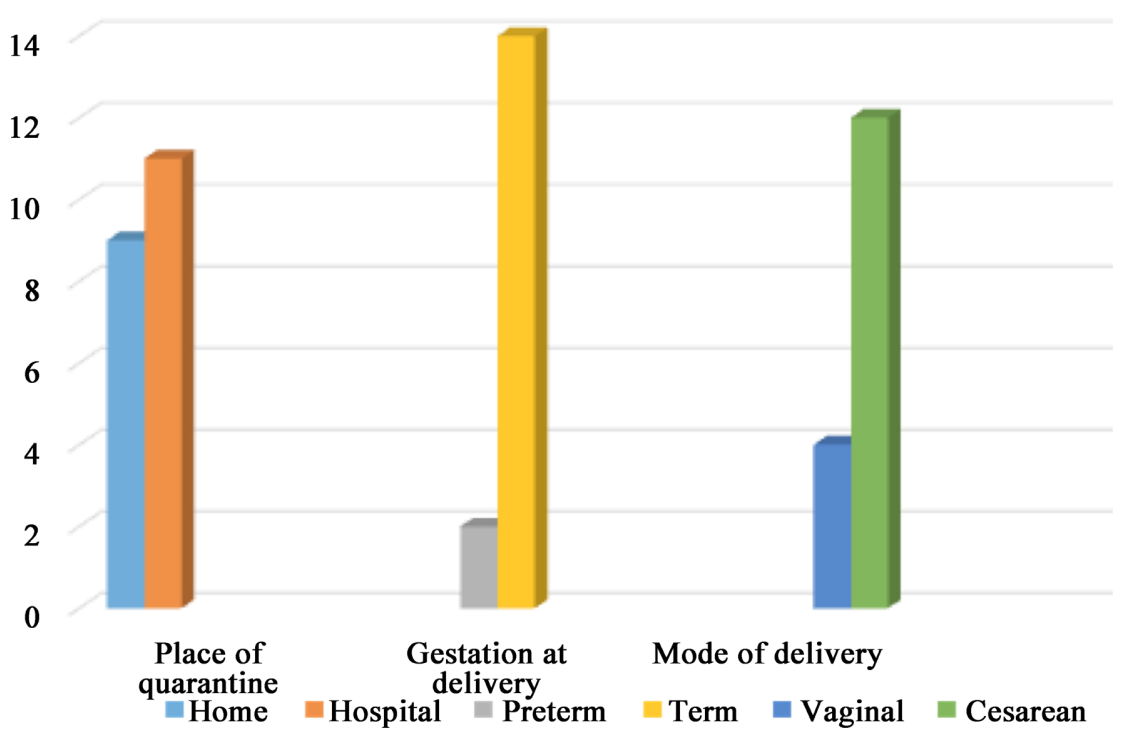

Figure 3. Shows comorbidities in pregnant women who are covid positive.

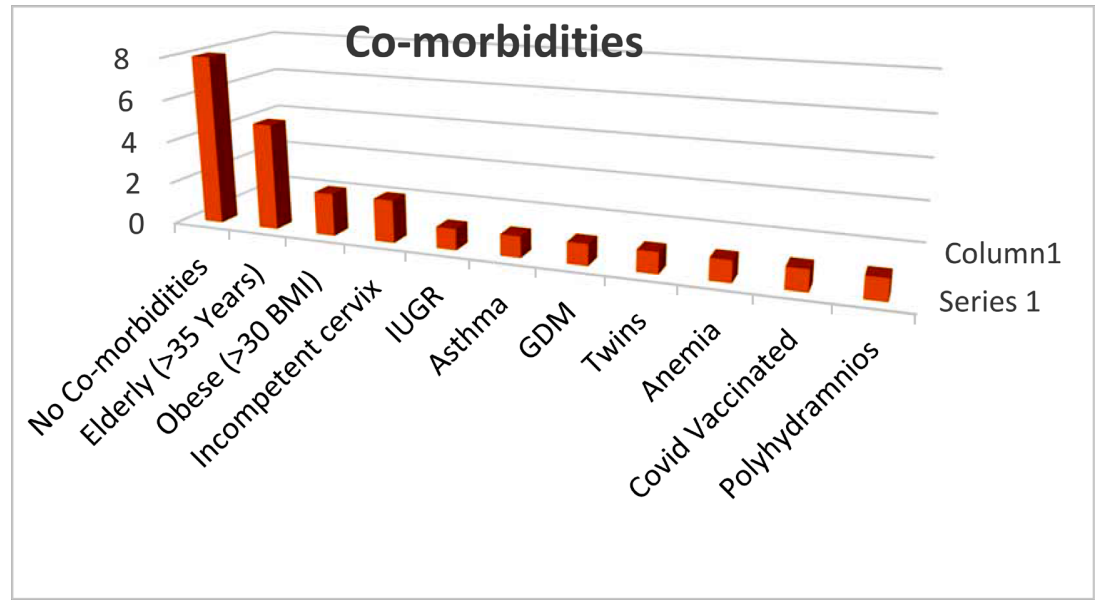

Figure 4. Neonatal outcomes.

positive pregnant women. Those deliveries could be due to obstetric reasons such as the pregnancy of twins and PPROM with incompetent cervix.

The preterm gestation and twin gestations were factored in when discussing about fetal growth

A total of 17 babies with a history of COVID positive in mothers have been delivered till now in our hospital over the study period. None of the babies delivered in the hospital were positive.

Babies with birth weight $<2.8 \mathrm{~kg}$ were 7 (41\%) out of which 3 were preterm babies (17\%) and appropriate for gestational age.

Two of them were early-onset small for date babies and 2 had intrauterine growth restriction (IUGR) (Figure 5).

The mothers of growth restricted babies had COVID 19 in their third trimester and were of Arab and South Asian ethnicity. 


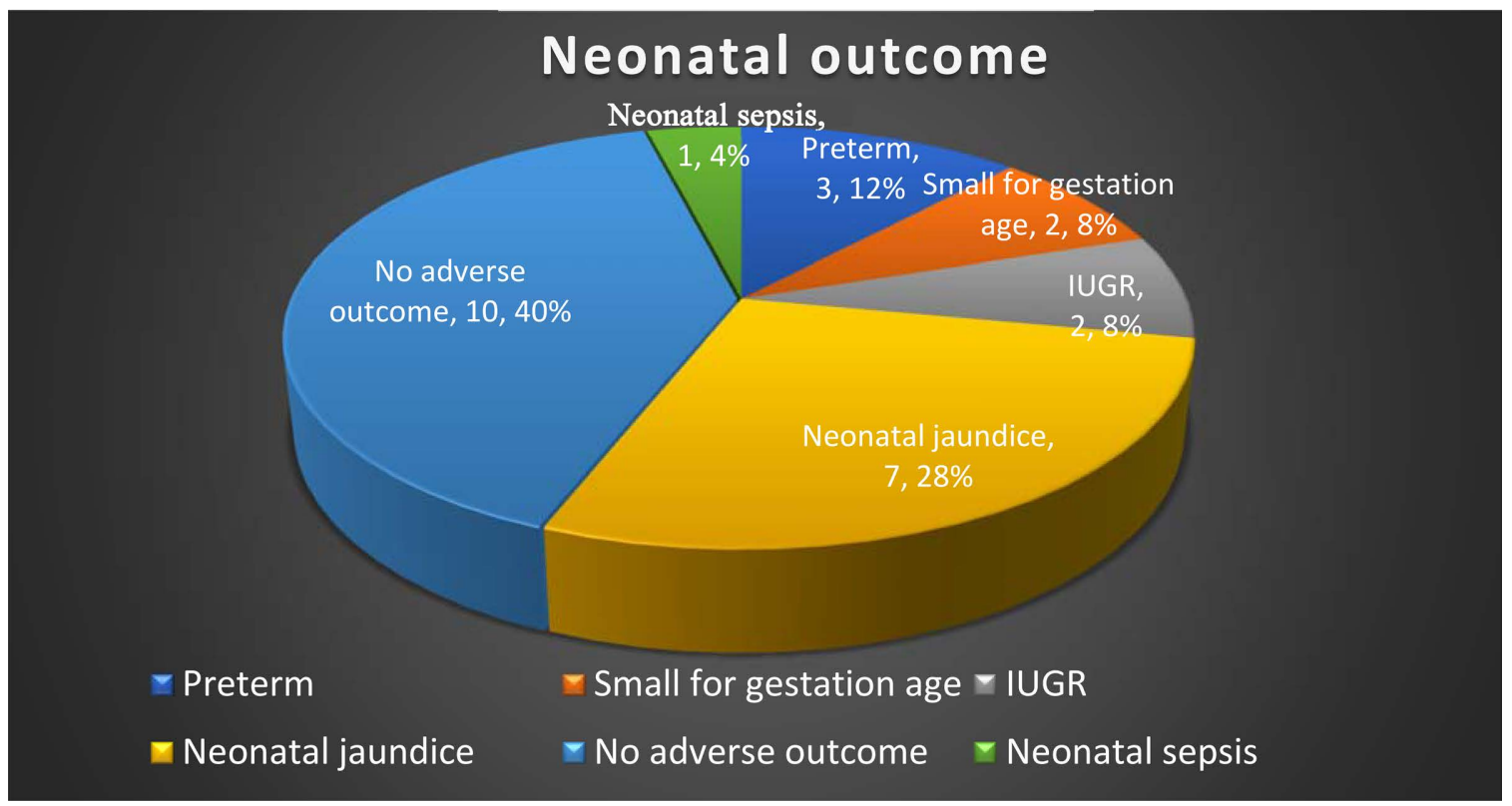

Figure 5. Neonatal outcomes.

Most of the babies did well in their postnatal period and the NICU admissions were for prematurity and neonatal jaundice.

There are several studies done that are like these studies and that have shown favourable outcomes in neonates. Danube et al. did a systemic review that confirmed that vertical transmission does not happen in neonates born to covid positive mothers and that they had favourable outcomes. Another systemic review by Karaby et al. showed no fatality in neonates [2]. However, another review done by Salem et al. showed the presence of vertical transmission [3].

Similar results to ours were none of the babies of covid positive mothers tested positive to covid [4] [5].

\section{Conclusions}

In our study group babies born to mothers who are covid positive had a favourable outcome and none of them tested positive to covid.

There was no proof of vertical transmission [6] [7].

In our study group, the rate of comorbid factors in pregnant women with COVID 19 was low and the feto-maternal outcome was favourable in most of them.

Majority of infections are seen in the third trimester [8].

Preterm incidence was $17 \%$ other studies showed incidence of $40 \%$ [9].

Given the physiologic and immune function changes in pregnancy, they might be considered at a higher risk of developing more complications, but it needs a longer duration of the study with larger sample size [10].

Statistical analysis could not be possible in our study due to the smaller sample size, and we plan to continue the study further in the future to obtain a larger pool of data to validate the findings more accurately. 
The incidence of covid positive mothers might not reflect today's covid situation because we carried out the study during the lockdown and there might be an increase in the incidence after lockdown.

We now see many pregnant women who took the COVID 19 vaccine during their conception period or after $1-3$ months of the vaccine.

In our study, one patient was vaccinated and got the COVID 19 positive later with mild symptoms and is now continuing with the pregnancy. So, this will be the consideration for our next phase of research, which can give us more insight into pregnancies with the COVID vaccine and their effect on the foetus and neonate.

\section{Conflicts of Interest}

The authors declare no conflicts of interest regarding the publication of this paper.

\section{References}

[1] Tripathi, S., Gogia, A. and Kakar, A. (2020) COVID-19 in Pregnancy: A Review. Journal of Family Medicine and Primary Care, 9, 4536-4540. https://doi.org/10.4103/jfmpc.jfmpc 71420

[2] Dube, R. and Kar, S.S. (2020) COVID-19 in Pregnancy: The Foetal Perspective-A Systematic Review. BMJ Paediatrics Open, 4, e000859. https://doi.org/10.1136/bmipo-2020-000859

[3] Salem, D., Katranji, F. and Bakdash, T. (2021) COVID-19 Infection in Pregnant Women: Review of Maternal and Fetal Outcomes. International Journal of Gynecology \& Obstetrics, 152, 291-298. https://doi.org/10.1002/ijgo.13533

[4] Gupta, P., Kumar, S. and Sharma, S.S. (2021) SARS-CoV-2 Prevalence and Maternal-Perinatal Outcomes among Pregnant Women Admitted for Delivery: Experience from COVID-19-Dedicated Maternity Hospital in Jammu, Jammu and Kashmir (India). Journal of Medical Virology, 93, 5505-5514. https://doi.org/10.1002/jmv.27074

[5] RCOG Guideline (2021) Coronavirus (COVID-19) Infection and Pregnancy. https://www.rcog.org.uk/en/guidelines-research-services/guidelines/coronavirus-pr egnancy/covid-19-virus-infection-and-pregnancy/

[6] Lopes de Sousa, Á.F., Carvalho, H.E.F., Oliveira, L.B., Schneider, G., Camargo, E.L.S., Watanabe, E., de Andrade, D., Fernandes, A.F.C., Mendes, I.A.C. and Fronteira, I. (2020) Effects of COVID-19 Infection during Pregnancy and Neonatal Prognosis: What Is the Evidence? International Journal of Environmental Research and Public Health, 17, Article No. 4176. https://doi.org/10.3390/ijerph17114176

[7] Chen, H.J., Guo, J.J., Wang, C., Luo, F., Yu, X.C., Zhang, W., Li, J., Zhao, D., Xu, D., Gong, Q., Liao, J., Yang, H., Hou, W. and Zhang, Y. (2020) Clinical Characteristics and Intrauterine Vertical Transmission Potential of COVID-19 Infection in Nine Pregnant Women: A Retrospective Review of Medical Records. The Lancet, 395, 809-815. https://doi.org/10.1016/S0140-6736(20)30360-3

[8] Salem, D., Katranji, F. and Bakdash, T. (2021) COVID-19 Infection in Pregnant Women: Review of Maternal and Fetal Outcomes. International Journal of Gynecology \& Obstetrics, 152, 291-298. https://doi.org/10.1002/ijgo.13533

[9] Yee, J., Kim, W., Han, J.M., et al. (2020) Clinical Manifestations and Perinatal Out- 
comes of Pregnant Women with COVID-19: A Systematic Review and Meta-Analysis. Scientific Reports, 10, Article ID: 18126.

https://doi.org/10.1038/s41598-020-75096-4

[10] Allotey, J., Stallings, E., Bonet, M., Yap, M., Chatterjee, S, Kew, T., et al. (2019) Clinical Manifestations, Risk Factors, and Maternal and Perinatal Outcomes of Coronavirus Disease in Pregnancy: Living Systematic Review and Meta-Analysis. BMJ, 370, m3320. https://doi.org/10.1136/bmj.m3320 